\title{
REDES SOCIAIS E INTERORGANIZACIONAIS
}

Redes sociais é um tema proeminente da sociologia contemporânea. Mas foi na década de 70 que as redes - sua formação, seu papel e impacto - passaram a ser tomadas como fundamentais para se explicar uma parcela significativa da vida econômica e das organizações quanto às suas conformações e dinâmicas. A abordagem das redes é al ternativa, por um lado, ao determinismo cultural - uma vez que elas são produto da "human agency" - e, por outro, à abordagem econômica neoclássica - na medida em que as relações entre indivíduos, e não os indivíduos isolados, é que são tomadas como unidade de análise. A seguir a Professora Ana Cristina Braga Martes, da FGVEAESP, apresenta alguns dos livros fundamentais para a compreensão do tema.

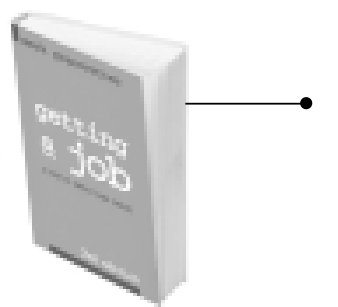

GETTING A JOB: A study of contacts and careers Mark Granovetter. Cambridge: Harvard University Press, 1974 (1 ${ }^{\text {st }}$. ed.). 251 p.

Essa pesquisa pioneira sobre formas de acesso a postos de trabalho introduziu a discussão sobre a importância e o papel das redes no mercado de trabal ho e na estrutura de oportunidades em geral.

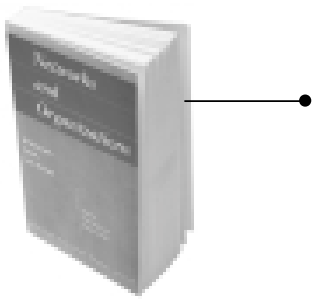

NETWORKS AND ORGANIZATIONS: Structure, form and action Nitin Nohria e Robert Ecles (eds.). Boston: Harvard Business School Press, 1992. 544 p.

Os autores reuniram neste volume os principais especialistas norte-americanos sobre análise organizacional - entre eles, Ronald Burt, Mark Granovetter e Paul DiM aggio que tratam do problema da mobilização da ação de indivíduos e grupos.

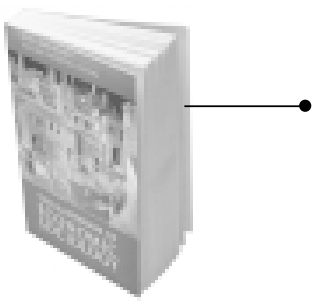

THE HANDBOOK OF ECONOMIC SOCIOLOGY Neil J. Smelser e Richard Swedberg (eds.). Princeton: Princeton University Press, 1994. $835 \mathrm{p}$.

0 livro traz um excelente balanço da bibliografia sobre redes interorganizacionais e vida econômica. 0 capítulo sobre redes, "Networks and Economic Life", escrito por Walter Powell e Laurel Smith-Doerr, traz uma detalhada análise das principais abordagens sobre o tema.

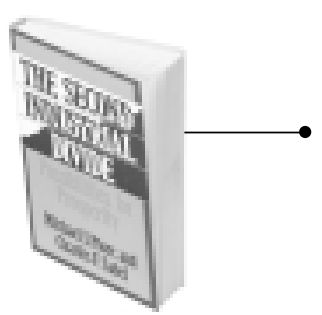

THE SECOND INDUSTRIAL DIVIDE: Possibilities for prosperity Michael J. Piore e Charles F. Sabel. New York: Basic Books, 1984. 345 p. O livro traz uma abordagem interdisciplinar, tomando as redes como uma espécie de lógica organizacional e de produção alternativa ao fordismo. Analisa de que modo a produção se torna altamente dependente do trabalho em rede entre as firmas.

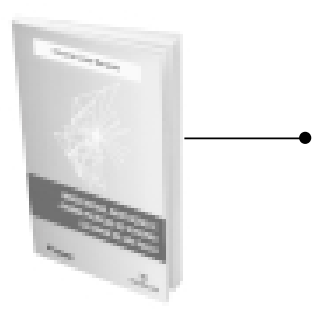

REDES SOCIAIS, INSTITUIÇÕES E ATORES POLÍTICOS NO GOVERNO DA CIDADE DE SÃO PAULO Eduardo Cesar Marques. São Paulo: Annablume/ Fapesp, 2003. 248p. São raros os trabalhos sobre redes no Brasil. O livro de Marques apresenta uma importante e original contribuição, ao fazer uso dessa abordagem para analisar aspectos da política institucional na cidade de São Paulo. 